\title{
ANALYTICAL CALCULATIONS OF THE VIBRATIONS OF VERTICAL STRUCTURES CONSIDERING THEIR DEAD WEIGHT
}

Scientific paper

\section{Yurii Krutii}

(Received: 23 September 2020; accepted: 23 June 2021)

Odessa State Academy of Civil Engineering and Architecture, Department of Information Technology and Applied Mathematics, $S c D$

Corresponding author: yurii.krutii@gmail.com

\section{Victor Vandynskyi}

Odessa State Academy of Civil Engineering and Architecture, Building mechanical Department, postgraduate student

\section{Petr Konstantinov}

Odessa State Academy of Civil Engineering and Architecture, Department metal, wooden and plastic structures, $P h D$

\begin{abstract}
This paper presents the results of studies on the analytical dependence between the value of a longitudinal distributed load and the frequency of free vibrations in a uniform rod. Based on the exact solution of the corresponding differential equation, a method for calculating vibrations in rod structures, while considering their dead weight, is implemented. The method algorithm is shown using the example of a rod with both ends clamped. This article contains graphs and analytical formulas for displaying dependencies. A table is provided that contains all the necessary coefficients to perform similar calculations for other boundary conditions. These results allow the physical and mechanical characteristics of a system to be used to determine the natural frequency of rod structures without using approximate methods.
\end{abstract}

Keywords: Rod structure; variable longitudinal force; bending vibration; natural frequency. 


\section{INTRODUCTION}

When designing structures, it is necessary to consider all possible influences to which they can be subjected during construction and operation. Most of these effects are dynamic. This issue is becoming increasingly relevant because of the increase in the height of modern construction, attempts to minimize the material consumption of structures, and development in areas with seismic activity. The dynamic parameters of structures can be estimated, based on an analysis of such characteristics as the frequencies and modes of natural vibrations. The presence of these data allows the stiffness and operability of the structure to be analyzed and the correctness of construction decisions to be evaluated, as well as ensuring a high-quality design.

Many materials and publications have been devoted to investigating the influence of longitudinal loads on the bending vibrations of various types of rod structures. In [1], based on the energy method, empirical formulas for studying the vibrations of uniform beams under various boundary conditions and axial loads were obtained. In [2], the authors studied the vibrations of frame structures by considering the influence of the axial load. An equivalent rod was used as a design model of buildings in this study. Its stiffness and weight should be evenly distributed along the length. Reference [3] is devoted to an experimental study on the influence of axial force on the vibration frequency of a rod. This study attempts to find a connection between theoretical models and phenomena occurring in the real world.

In [4], the vibrations of clamped rods were studied using numerical methods. Specifically, the influence of the mass and damage on the natural frequency of vibrations was studied. The bending vibrations of structures, considering their own weight, were studied in [5]. Similar to most of these publications, approximate calculation methods were used. In [6], the frequencies of free and seismic vibrations of a building were determined using simulations in software systems. In [7], the influence of a variable longitudinal force on a rod with free ends was determined. Reference [8] investigated uniform rods under a constant longitudinal force. Using graphs, it presented how the influence of changes in force was dependent on the frequencies of natural vibrations and the main modes of vibration for all types of boundary conditions.

Often in scientific literature, the longitudinal force is assumed to be constant along the length of a structure [8-12]. However, it is clear that, in real life, the longitudinal force has different values at different points of the structure. A common design scheme for studies on the bending vibrations of buildings and structures is the uniform rod under a variable longitudinal force, which represents the dead weight of the structure. For such a physical phenomenon, the mathematical model is typically represented by a differential equation with variable coefficients $[13,14]$, which makes it difficult to construct an exact solution.

The exact solution of the corresponding equation of motion obtained in [15], using the direct integration method, made it possible to take the study of vibrations of rod structures to a qualitatively new level. It also made it possible to establish analytical relationships between the characteristics of a mechanical system and the frequencies of natural vibrations [16]. The present work is the final one in the study of this problem and aims to demonstrate the steps for calculating the frequency of natural vibrations in the rods and to present the main results found by the authors.

\section{INITIAL EQUATION AND ANALYTICAL SOLUTIONS}

In construction problems, the dead weight is considered as a longitudinal distributed load, which means that the rods are in a vertical position. In the specialized literature related to construction problems [14], four main schemes are usually considered:

- A cantilever rod with a free upper end (free - clamped);

- A hinged rod (pinned - pinned);

- A rod, clamped at the lower end and hinged at the upper end (clamped - pinned);

- A rod with both ends clamped (clamped - clamped).

In this paper, the step-by-step algorithm of the study will be presented, using the example of a rod with both ends clamped. Fig. 1 shows the general scheme of the vibrations of the rod. Fig. 2 shows the external and internal forces acting on the element of the rod. 


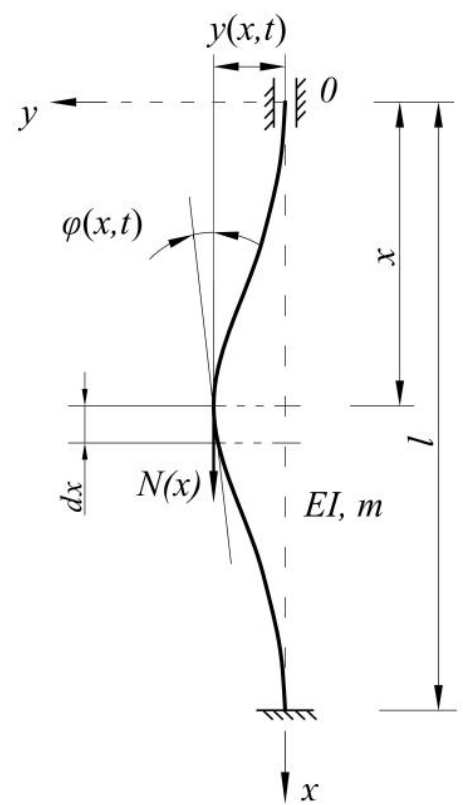

Figure 1 Bending vibrations of the rod, considering the longitudinal force

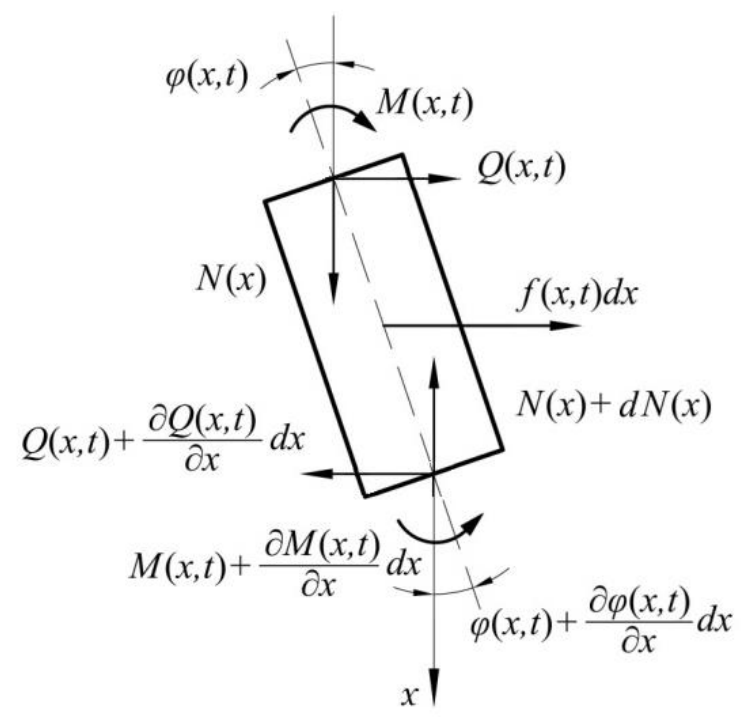

Figure 2 Internal and external forces acting on the rod element

List of symbols:

$E I$ - Flexural rigidity of a rod;

$m$ - Intensity of the distributed mass (own weight) of the rod;

$N(x)=q x$ - Variable axial (compressive) force, where $q$ - weight per unit length of column;

$y(x, t)$ - Cross motion of the axis point of the rod with coordinate $x$ at time $t$ (dynamic deflection);

$\varphi(x, t)$ - Dynamic angular displacement;

$M(x, t)$ - Dynamic bending moment;

$Q(x, t)$ - Dynamic shear force;

$f(x, t)$ - Intensity of the inertial forces that appear during vibration (D'Alembert's force).

As has been shown [12-14, 17], the mathematical model of such a physical phenomenon is a partial differential equation with variable coefficients:

$$
E I \frac{\partial^{4} y}{\partial x^{4}}+q \frac{\partial}{\partial x}\left(x \frac{\partial y}{\partial x}\right)+m \frac{\partial^{2} y}{\partial t^{2}}=0
$$

For the dynamic parameters of the rod state, the following view is taken:

$y(x, t)=v(x) T(t) ; \quad \varphi(x, t)=\varphi(x) T(t) ; M(x, t)=M(x) T(t) ; Q(x, t)=Q(x) T(t)$

Where:

$v(x)$-amplitude value of the transverse deflection, which depends only on variable $x$;

$T(t)$ - function of time $t$;

$\varphi(x), M(x), Q(x)$-amplitude functions that are connected by the following equalities:

$\varphi(x)=v^{\prime}(x) ; M(x)=-E I v^{\prime \prime}(x) ; Q(x)=M^{\prime}(x)-N(x) v^{\prime}(x)$.

In [15], an exact solution of (1) was presented. They provided the formulas for the uniform rod's state parameters, expressed in terms of the initial parameters and fundamental dimensionless functions, which have the following form:

$$
\begin{aligned}
& v(x)=v(0) X_{1}(x)+\varphi(0) l X_{2}(x)-M(0) \frac{l^{2}}{E I} X_{3}(x)-Q(0) \frac{l^{3}}{E I} X_{4}(x) \\
& \varphi(x)=v(0) \frac{1}{l} \tilde{X}_{1}(x)+\varphi(0) \tilde{X}_{2}(x)-M(0) \frac{l}{E I} \tilde{X}_{3}(x)-Q(0) \frac{l^{2}}{E I} \tilde{X}_{4}(x)
\end{aligned}
$$

Krutii, Y, Vandynskyi, V, Konstantinov, P 


$$
\begin{aligned}
& M(x)=-v(0) \frac{E I}{l^{2}} \hat{X}_{1}(x)-\varphi(0) \frac{E I}{l} \hat{X}_{2}(x)+M(0) \hat{X}_{3}(x)+Q(0) l \hat{X}_{4}(x) \\
& Q(x)=-v(0) \frac{E I}{l^{3}}\left(\hat{X}_{1}(x)+\alpha \frac{x}{l} \tilde{X}_{1}(x)\right)-\varphi(0) \frac{E I}{l^{2}}\left(\hat{X}_{2}(x)+\alpha \frac{x}{l} \tilde{X}_{2}(x)\right)+ \\
& +M(0) \frac{1}{l}\left(\hat{X}_{3}(x)+\alpha \frac{x}{l} \tilde{X}_{3}(x)\right)+Q(0)\left(\hat{X}_{4}(x)+\alpha \frac{x}{l} \tilde{X}_{4}(x)\right)
\end{aligned}
$$

Where:

$$
\alpha=\frac{q l^{3}}{E I}
$$

$X_{n}(x), \tilde{X}_{n}(x), \hat{X}_{n}(x), \hat{X}_{n}(x) \quad(n=1,2,3,4)$ - fundamental dimensionless functions, which are defined in [15].

The above formulas include a dimensionless parameter $\alpha$. It is believed that attention should be particularly focused on it because this value characterizes the mechanical system.

The presence of these equations in the form of dimensionless values makes it possible to further study the analytical dependencies. It should be noted that the formulas can be used for any boundary condition.

\section{INVESTIGATION OF THE ROD'S VIBRATIONS}

The dynamic boundary conditions of a rod with both ends clamped have the following form:

$$
y(0, t)=0 ; \varphi(0, t)=0 ; y(l, t)=0 ; \varphi(l, t)=0 .
$$

Implementing these conditions using the exact formulas (2)-(6) leads to a frequency equation. In terms of the dimensionless function, the frequency equation for the current boundary conditions has the following form:

$$
X_{3}(l) \tilde{X}_{4}(l)-\tilde{X}_{3}(l) X_{4}(l)=0 .
$$

Alternatively, this can be written such that the left part contains a convergent power series of dimensionless parameter $K$ :

$$
\eta_{0}+\eta_{1} K^{2}+\eta_{2} K^{4}+\eta_{3} K^{6}+\ldots=0
$$

The dimensionless coefficients of the equation $\eta_{k}(k=1,2,3, \ldots)$ can be determined by the following formulas:

$$
\eta_{k}=\sum_{j=0}^{k}\left(\beta_{3, j}(l) \tilde{\beta}_{4, k-j}(l)-\tilde{\beta}_{3, j}(l) \beta_{4, k-j}(l)\right)
$$

Where:

$$
\begin{aligned}
& \beta_{n, 0}(l)=c_{n, 0,0}+\sum_{j=1}^{\infty}(-1)^{j} \alpha^{j} c_{n, 0, j} \quad(n=3,4), \\
& \beta_{n, k}(l)=c_{n, k, 0}+\sum_{j=1}^{\infty}(-1)^{j} \alpha^{j} c_{n, k, j}(k=1,2,3, \ldots), \\
& \tilde{\beta}_{n, 0}(l)=f_{n, 0,0} c_{n, 0,0}+\sum_{j=1}^{\infty}(-1)^{j} \alpha^{j} f_{n, 0, j} c_{n, 0, j}, \\
& \tilde{\beta}_{n, k}(l)=f_{n, k, 0} c_{n, k, 0}+\sum_{j=1}^{\infty}(-1)^{j} \alpha^{j} f_{n, k, j} c_{n, k, j} .
\end{aligned}
$$

The following set of recurrence formulas is used to determine the dimensionless coefficients of the series [15]:

$$
\begin{aligned}
c_{n, 0,0} & =\frac{1}{(n-1) !} ; \\
c_{n, k, 0} & =\frac{1}{(n+4 k-1) !} ; \\
c_{n, 0, j} & =\frac{(n-1)(n+2) \ldots(n+3 j-4)}{(n+3 j-1) !} ;
\end{aligned}
$$


Where:

$$
c_{n, k, j}=\frac{c_{n, k-1, j}+\left(f_{n, k, j}-3\right)^{2} c_{n, k, j-1}}{\left(f_{n, k, j}-3\right)\left(f_{n, k, j}-2\right)\left(f_{n, k, j}-1\right) f_{n, k, j}},
$$

$$
f_{n, k, j}=n+4 k+3 j-1 \quad(n=3,4)(k=0,1,2, \ldots)(j=0,1,2, \ldots) .
$$

\subsection{Natural frequencies of the rod}

Because the solution of the equation was constructed in terms of fundamental functions, it was possible to obtain an analytical representation of the spectrum of vibration frequencies [15]:

$$
p_{j}=\frac{K_{j}}{l^{2}} \sqrt{\frac{E I}{m}}(j=1,2,3, \ldots)
$$

Here, $K_{j}$ includes the dimensionless coefficients that are dependent on $q$ and are determined by the frequency equation. Therefore, the task of determining the frequencies of the clamped rod was reduced to determining the dimensionless vibration coefficients. From the above formulas, it is obvious that the values of the roots $K_{1}, K_{2}, K_{3}, \ldots$ depend on the dimensionless parameter $\alpha$. The relevant range of change for this parameter will be set.

Earlier in [18], the authors investigated the stability of rods loaded with their own weights under various boundary conditions. The obtained results were also confirmed by the stability theory [19, 20]. It was found that a clamped rod under the action of a distributed load will lose stability when:

$$
q_{c r}=q_{c r, 1}=74.6286 \frac{E I}{l^{3}}
$$

Therefore, it is meaningless from a practical point of view to consider the vibrations of a rod with $q$ values greater than $q_{c r}$. Therefore, the values of longitudinal loading relevant to the study lie within the interval $0 \leq q \leq q_{c r}$.

Substituting $q=q_{c r}$ into formula (7) gives the maximum possible value of $\alpha$ :

$$
\alpha_{\max }=\frac{q_{c r} l^{3}}{E I}=74.6286 \text {. }
$$

Hence, the values of $\alpha$ relevant for investigation lie in the interval $0 \leq \alpha \leq 74.6286$.

Table 1 shows the results of calculating the first three vibration coefficients for the values of parameter $\alpha$ from the specified permissible interval, equidistant from each other in increments of 7.4629 .

Table 1 Vibration coefficients

\begin{tabular}{cccc}
\hline$\alpha$ & $K_{1}$ & $K_{2}$ & $K_{3}$ \\
\hline 0.0000 & 22.3732 & 61.6729 & 120.9034 \\
7.4629 & 21.3154 & 60.2594 & 119.3652 \\
14.9257 & 20.1858 & 58.8033 & 117.8027 \\
22.3886 & 18.9704 & 57.3009 & 116.2147 \\
29.8514 & 17.6495 & 55.7484 & 114.6003 \\
37.3143 & 16.1952 & 54.1411 & 112.9584 \\
44.7772 & 14.5649 & 52.4738 & 111.2879 \\
52.2400 & 12.6869 & 50.7405 & 109.5874 \\
59.7029 & 10.4228 & 48.9341 & 107.8557 \\
67.1657 & 7.4178 & 47.0460 & 106.0915 \\
74.6286 & 0.0000 & 45.0657 & 104.2931 \\
\hline
\end{tabular}

It is evident that, as parameter $\alpha$ approaches the maximum value from the stability conditions, and therefore, the longitudinal load approaches its critical value, the first vibration frequency of the rod approaches 0 . The values of the second and third frequencies decrease. To explain the decrease of the coefficient's $K_{1}$ values, the theory of stability is again considered. 


\subsection{Limits of vibration-coefficient values}

Consider the same design scheme: a uniform rod under a longitudinal distributed load. The stability of such a rod is described by the well-known equation [20, 21]:

$\operatorname{EIy}^{\prime \prime \prime \prime}(x)+q\left(x y^{\prime}(x)\right)^{\prime}=0$

After performing the necessary calculations [18], the critical value of the load (11) is obtained. However, considering the presence of neighboring figures of equilibrium [21] and using the results of [18], the solution of equation (12) can be satisfied by other values:

$$
q_{c r, 2}=149.0095 \frac{E I}{l^{3}} ; \quad q_{c r, 3}=381.3606 \frac{E I}{l^{3}} .
$$

Substituting the above values of $q_{c r}$ into formula (7), the corresponding values of parameter $\alpha$ are obtained. Now, consider the vibrations of a clamped rod on a new interval $0 \leq \alpha \leq 381.3606$.

Similarly, after performing the necessary calculations and obtaining a set of values for vibration coefficients $K_{1}, K_{2}, K_{3}$, graphs of the dependence of the vibration coefficients on the change in parameter $\alpha$ were constructed:

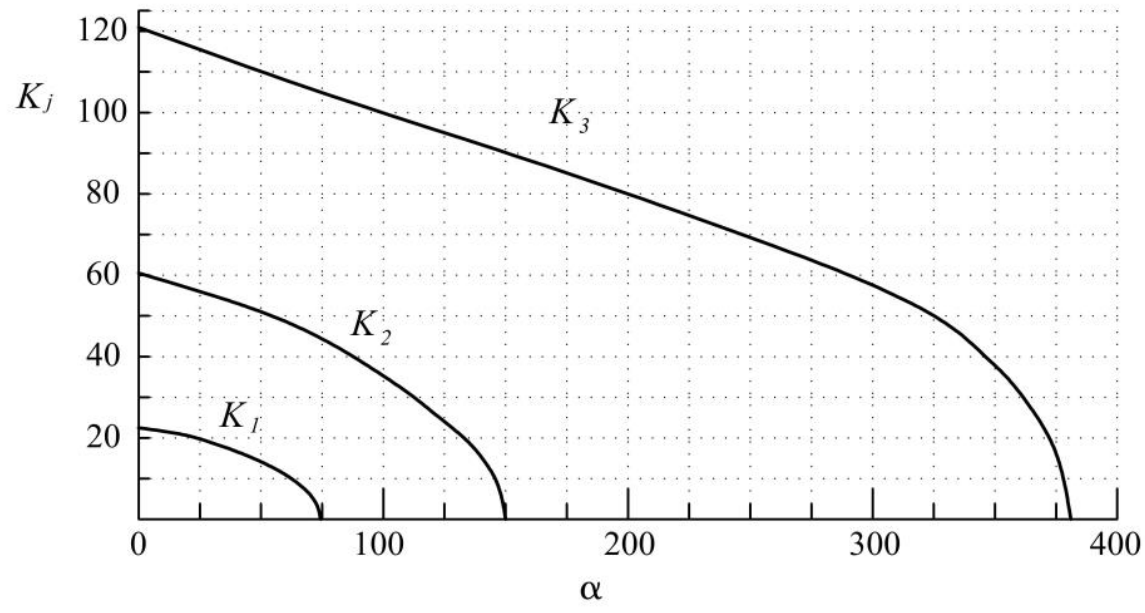

Figure 3 Graph of the dependence of vibration coefficients on parameter $\alpha$

As can be seen, the vibration coefficients (and, consequently, the value of the natural-vibration frequency) reach zero when parameter $\alpha$ of the corresponding form of stability reaches a critical value. Despite the existence of neighboring figures of equilibrium, rod vibrations are usually considered within the limits of the usual perception of stability; that is, until $\alpha$ exceeds the critical value of the first form of stability.

\subsection{Analytical dependencies}

Considering coefficient $K_{j}$ as a function of variable $\alpha$, and having a set of values of this function, it can be approximated using a polynomial. To achieve a highly accurate approximation, the degree of the polynomial was chosen such that the determination coefficient was not less than 0.9999. A high value for the coefficient of determination was also achieved because of the large array of calculated values obtained for different values of $K_{j}$.

The calculations showed that, for the third and second vibration coefficients, the value of the determination coefficient will be practically equal to unity, by the quadratic approximation. For the first coefficient, through the interval with a sharp decline in the graph, it was necessary to approximate it with a sixth-degree polynomial. The final formulas have the following form:

$$
\begin{aligned}
K_{1}= & 22.3732+0.0074 \alpha-0.02897 \alpha^{2}+0.001864 \alpha^{3}-0.0000541 \alpha^{4}+7.2 \cdot 10^{-7} \alpha^{5}- \\
& -3.5 \cdot 10^{-9} \alpha^{6}
\end{aligned}
$$




$$
\begin{aligned}
& K_{2}=61.6729-0.18171 \alpha-0.00054 \alpha^{2} \\
& K_{3}=120.9034-0.20339 \alpha-0.00026 \alpha^{2}
\end{aligned}
$$

Substituting (13)-(15) into (10), the following analytical formulas can be obtained for determining the first three frequencies of free vibrations of clamped-end rod structures:

$$
\begin{aligned}
& p_{1}=\left(22.3732+0.0074 \alpha-0.02897 \alpha^{2}+0.001864 \alpha^{3}-0.0000541 \alpha^{4}+7.2 \cdot 10^{-7} \alpha^{5}-\right. \\
& \left.-3.5 \cdot 10^{-9} \alpha^{6}\right) \frac{1}{l^{2}} \sqrt{\frac{E I}{m}} \\
& p_{2}=\left(61.6729-0.18171 \alpha-0.00054 \alpha^{2}\right) \frac{1}{l^{2}} \sqrt{\frac{E I}{m}} \\
& p_{3}=\left(120.9034-0.20339 \alpha-0.00026 \alpha^{2}\right) \frac{1}{l^{2}} \sqrt{\frac{E I}{m}}
\end{aligned}
$$

With these formulas, and knowing the characteristics $q, l q, l$ and $E I$, it is possible to determine the vibration frequencies of the rod structures, considering their own weight, without using approximate methods.

A relationship can be established between frequencies $p_{1}, p_{2}, p_{3}$ and the corresponding vibrational frequencies of the rod without considering its own weight $\omega_{1}, \omega_{2}, \omega_{3}$. Recall that they are determined by the following well-known formulas [11]:

$$
\omega_{1}=\frac{22.3732}{l^{2}} \sqrt{\frac{E I}{m}} ; \omega_{2}=\frac{61.6729}{l^{2}} \sqrt{\frac{E I}{m}} ; \omega_{3}=\frac{120.9034}{l^{2}} \sqrt{\frac{E I}{m}} .
$$

Obviously, these formulas are partial cases of (16)-(18). By comparing the vibration coefficients, it is easy to establish a connection between frequencies, with and without considering their own weights:

$$
\begin{aligned}
& \frac{p_{1}}{\omega_{1}}=1+0.00033 \alpha-0.00130 \alpha^{2}+8.33 \cdot 10^{-5} \alpha^{3}-5.4 \cdot 10^{-5} \alpha^{4}+3.2 \cdot 10^{-8} \alpha^{5}-1.56 \cdot 10^{-10} \alpha^{6} ; \\
& \frac{p_{2}}{\omega_{2}}=1-0.00295 \alpha-8.8 \cdot 10^{-6} \alpha^{2} ; \\
& \frac{p_{3}}{\omega_{3}}=1-0.00168 \alpha-2.15 \cdot 10^{-6} \alpha^{2} .
\end{aligned}
$$

Formula (7) may also be submitted in the form:

$$
\alpha=74.6286 \frac{q}{q_{c r}} .
$$

Substituting the ratio of the frequencies for parameter $\alpha$ produces the ratio of the frequency in terms of the value of the longitudinal load $q$ :

$$
\begin{aligned}
& \frac{p_{1}}{\omega_{1}}=1+0.02469 \frac{q}{q_{c r}}-7.21263\left(\frac{q}{q_{c r}}\right)^{2}+34.63602\left(\frac{q}{q_{c r}}\right)^{3}-75.02673\left(\frac{q}{q_{c r}}\right)^{4}+ \\
& +74.5226\left(\frac{q}{q_{c r}}\right)^{5}-27.03711\left(\frac{q}{q_{c r}}\right)^{6} \\
& \frac{p_{2}}{\omega_{2}}=1-0.21989 \frac{q}{q_{c r}}-0.04877\left(\frac{q}{q_{c r}}\right)^{2} \\
& \frac{p_{3}}{\omega_{3}}=1-0.12555 \frac{q}{q_{c r}}-0.01198\left(\frac{q}{q_{c r}}\right)^{2}
\end{aligned}
$$

Krutii, Y, Vandynskyi, V, Konstantinov, P 
These relationships can be represented graphically.

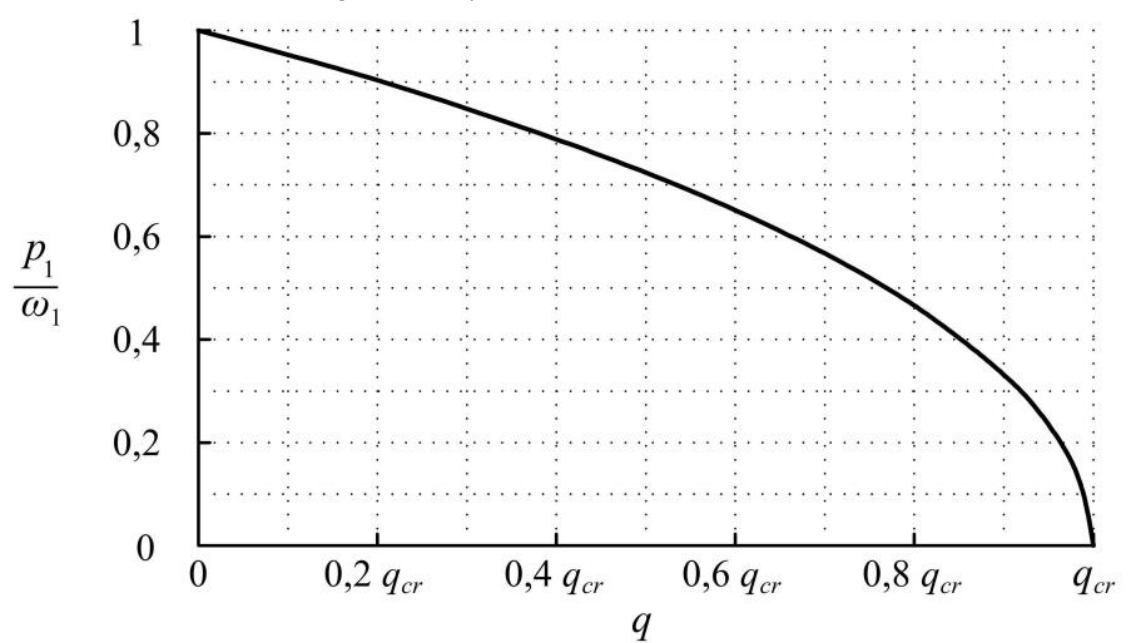

Figure 4 Graph of the dependence of $p_{1} / \omega_{1}$ on the longitudinal load $q$

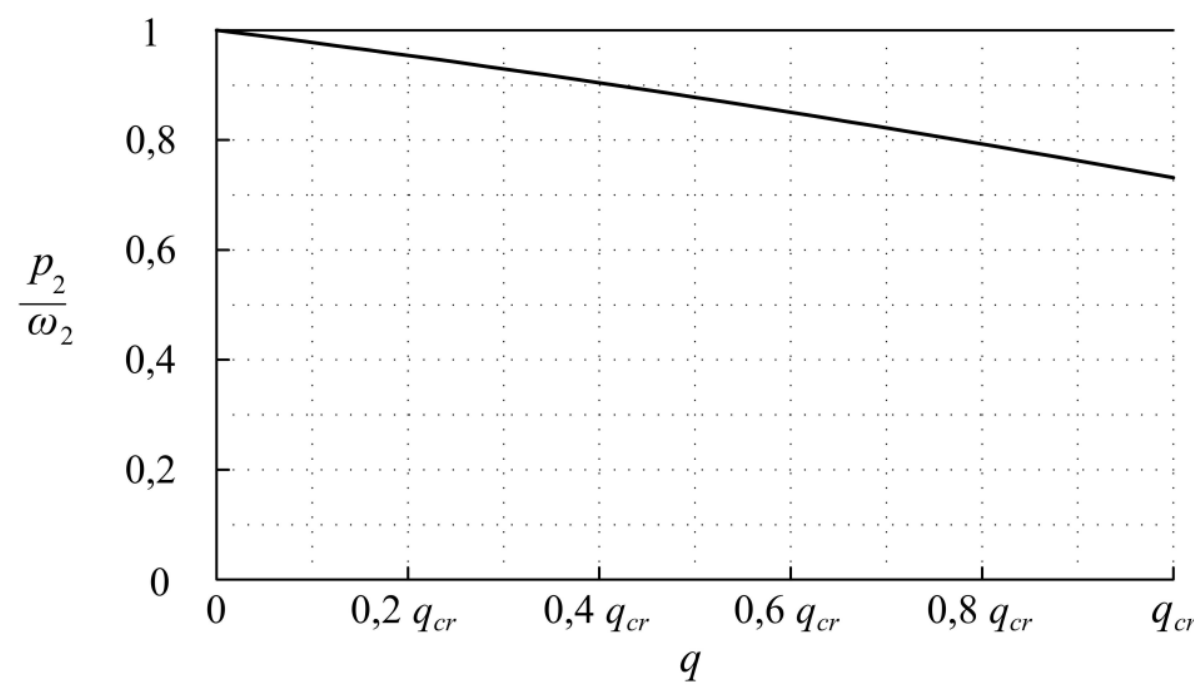

Figure 5 Graph of the dependence of $p_{2} / \omega_{2}$ on the longitudinal load $q$ 

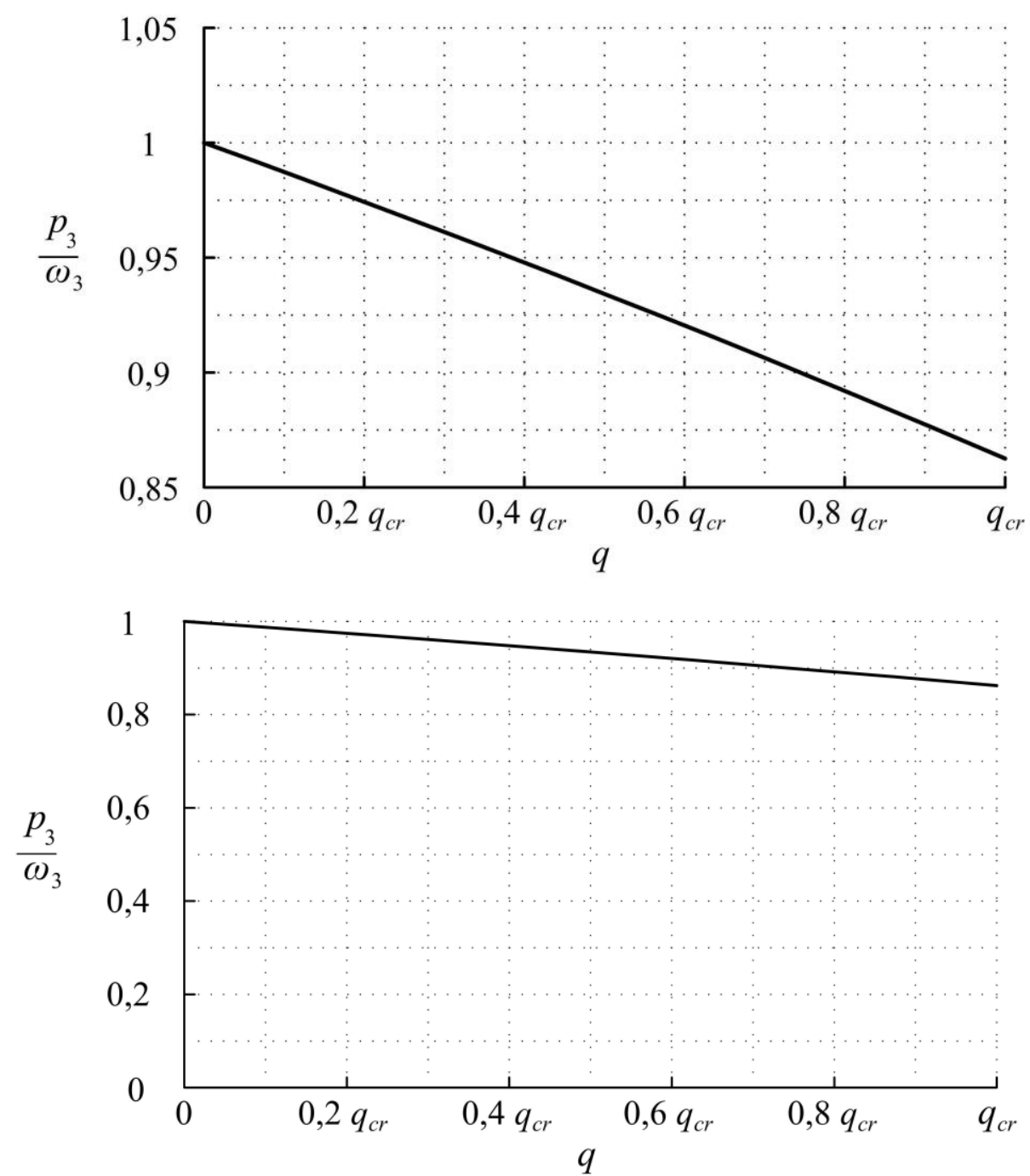

Figure 6 Graph of the dependence of $p_{3} / \omega_{3}$ on the longitudinal load $q$

By performing the same calculations for rods with other boundary conditions, the corresponding values for the vibration coefficients $K_{j}(j=1,2,3)$ and the formulas for the frequency of natural vibrations are obtained.

Table 2 Summary table

\begin{tabular}{lll}
\hline Type & Drawing & \multicolumn{1}{c}{ Information } \\
\hline & & $0 \leq \alpha \leq 7.8373$ \\
& $M(0)=0 ; Q(0)=0$ \\
& $y(l)=0 ; \varphi(l)=0$ \\
Free & $K_{1}=3.5160-0.0288 \alpha-0.33434 \alpha^{2}+0.1984528 \alpha^{3}-$ \\
& $-0.0545128 \alpha^{4}+0.006863 \alpha^{5}-0.0003252 \alpha^{6}$ \\
& & $K_{2}=22.0345-0.1959 \alpha-0.0010 \alpha^{2}$ \\
& & $K_{3}=61.6972-0.2022 \alpha-0.0004 \alpha^{2}$ \\
\end{tabular}

Krutii, Y, Vandynskyi, V, Konstantinov, P 


\begin{tabular}{|c|c|}
\hline $\begin{array}{l}\text { Pinned } \\
\text { Pinned }\end{array}$ & $\begin{array}{l}0 \leq \alpha \leq 18.5687 \\
y(0)=0 ; M(0)=0 \\
y(l)=0 ; M(l)=0 \\
K_{1}=9.8696-0.03217 \alpha-0.23408 \alpha^{2}+0.060923 \alpha^{3}- \\
-0.007097 \alpha^{4}+0.0003757 \alpha^{5}-0.0000074 \alpha^{6} \\
K_{2}=39.4784-0.2491 \alpha-0.0011 \alpha^{2} \\
K_{3}=88.8264-0.24984 \alpha-0.00044 \alpha^{2}\end{array}$ \\
\hline $\begin{array}{l}\text { Pinned } \\
\text { Clamped }\end{array}$ & $\begin{array}{l}0 \leq \alpha \leq 52.5007 \\
y(0)=0 ; M(0)=0 \\
y(l)=0 ; \varphi(l)=0 \\
K_{1}=15.4182-0.00323 \alpha-0.03941 \alpha^{2}+0.003597 \alpha^{3}- \\
-0.0001472 \alpha^{4}+0.0000027 \alpha^{5}-1.9 \cdot 10^{-8} \alpha^{6} \\
K_{2}=49.9646-0.1809 \alpha-0.00059 \alpha^{2} \\
K_{3}=104.2477-0.20267 \alpha-0.00028 \alpha^{2}\end{array}$ \\
\hline $\begin{array}{l}\text { Clamped } \\
\text { Clamped }\end{array}$ & $\begin{array}{l}0 \leq \alpha \leq 74.6286 \\
y(0)=0 ; \varphi(0)=0 \\
y(l)=0 ; \varphi(l)=0 \\
K_{1}=22.3732+0.0074 \alpha-0.02897 \alpha^{2}+0.001864 \alpha^{3}- \\
-0.0000541 \alpha^{4}+7.2 \cdot 10^{-7} \alpha^{5}-3.5 \cdot 10^{-9} \alpha^{6} \\
K_{2}=61.6729-0.18171 \alpha-0.00054 \alpha^{2} \\
K_{3}=120.9034-0.20339 \alpha-0.00026 \alpha^{2}\end{array}$ \\
\hline
\end{tabular}

The parameters given in Table 2 make it easy to calculate the frequency of the natural vibrations of the rods, considering their own weight, without using applications and approximate methods.

The values of the vibration coefficients for the rods, without considering their own weights, are already known $[11,21]$. These data are listed in a separate table.

Table 3 Vibration coefficients for weightless rods

\begin{tabular}{cccc}
\hline & $\begin{array}{c}\text { Free } \\
\text { Clamped }\end{array}$ & $\begin{array}{c}\text { Pinned } \\
\text { Pinned }\end{array}$ & $\begin{array}{c}\text { Pinned } \\
\text { Clamped }\end{array}$ \\
\hline$K_{1}$ & 3.5160 & 9.8696 & 15.4182 \\
$K_{2}$ & 22.0345 & 39.4784 & 49.9649 \\
$K_{3}$ & 61.6972 & 88.8264 & 104.2477 \\
\hline
\end{tabular}

By determining the vibration frequencies of the rods by considering their own weight, one can determine the relationship between the natural-frequency values by taking their own weight into account for some conditions, and without taking it into account for other types of boundary conditions.

\section{CONCLUSION}

Among the results of the work, the following should be highlighted:

1. Formulas for the first three frequencies of natural vibrations of the rod system were obtained in an analytical form. 
2. The relationship between the vibration frequencies, with and without considering the dead weight of the structure, was determined in an analytical form. It was established that a rod's own weight leads to a decrease in the frequency of natural vibrations, in comparison with the corresponding frequencies of a weightless rod. 3. The larger the value of the longitudinal load, the greater the difference between the vibration frequencies. When the value of the longitudinal load is increased to critical, the value of the rod's corresponding vibration frequency approaches 0 .

Table 2 shows all the necessary parameters, further simplifying the process of determining the frequency of natural vibrations, considering their own weight. Actually, determining the frequency is reduced to determining the vibration coefficients from known analytical formulas. The presence of results allows the vibrations of the rod structures to be calculated, without using approximate methods.

\section{References}

[1] Luo R. 2014: Formulating frequency of uniform beams with tip mass under various axial loads, Proceedings of the Institution of Mechanical Engineers, Part C: Journal of Mechanical Engineering Science, 228 (1), pp. 6776. https://doi.org/10.1177/0954406213482065

[2] Ghandi, E.; Rafezy, B. 2016: The effect of axial loads on free vibration of symmetric frame structures using continuous system method, Journal of Structural and Construction engineering, 3 (2), pp. 86-100.

[3] Nandi, A.; Neogy, S.; Roy, D. 2010: A simple experiment to demonstrate the effect of axial force on natural frequency of transverse vibration of a beam, International Journal of Mechanical Engineering Education, 38 (1), pp. 1-8. https://doi.org/10.7227//JMEE.38.1.1

[4] Vader, S. S.; Raikar, V. A. 2017: Experimental and numerical analysis of clamped-clamped composite beam, International Journal of Engineering Research \& Technology (IJERT), 6 (4), pp. 787-791. https://doi.org/10.17577/IJERTV6IS040630

[5] Zharnitskiy, V. I.; Sharipov Sh. Sh. 2013: Poperechnye kolebaniya sooruzheniy s ucheton verticalnoy nagruzki ot sobstvennoho vesa [in Russian], Earthquake engineering. Constructions safety, 3, pp. 28-30.

[6] Nikitina, E. A.; Hazov, P. A.; Generalova, A. A.; Sankina N. V. 2018: Opredeleniye chastot i form sobstvennyh i seismicheskih kolebaniy mnogoetazhnogo zdaniya gostinnitsy [in Russian], Vestnik VRO RAASN, 21, pp. 195-199.

[7] Nihous, G. C. 1997: On the continuity of the boundary value problem for vibrating free-free straight beams under axial loads, Journal of sound and vibration, 200 (1), pp. 110-119. https://doi.org/10.1006/jsvi.1996.0642

[8] Shaker, F. J. 1975: Effect of axial load on mode shapes and frequencies of beams, Lewis Research Center Report NASA, Cleveland, Ohio, USA

[9] Weaver, Jr. W.; Timoshenko, S. P.; Young D. H. 1990: Vibration problems in engineering, John Wiley \& Sons

[10] Babakov, I. M. 2004: Theory of Vibrations [in Russian], Drofa, Moskow, Russia

[11] Rao, S. S. 2010: Mechanical vibrations, 5th Edition, Pearson Education, USA

[12] Balachandran, B.; Magrab, E. B. 2008: Vibrations, Cengage Learning, Canada

[13] Vasilenko, M. V.; Alekseychuk, O. M. 2004: Teoriya kolyvan' i stiykosti ruhu [in Ukrainian], Vyscha shkola

[14] Khachiyan, E. Ye. 1973: Seysmicheskoye vozdeystvie na vysotnyie zdaniya i sooruzheniya [in Russian], Ayastan

[15] Krutii, Yu.; Suriyaninov, M.; Vandynskyi, V. 2017: Exact solution of the differential equation of transverse oscillations of the rod taking into account own weight, MATEC Web of Conferences, 116, p. 02022, https://doi.org/10.1051/matecconf/201711602022

[16] Krutii, Yu.; Suriyaninov, M.; Vandynskyi, V. 2019: Analytic formulas for the cantilever structures' natural frequencies with taking into account the dead weight, Materials Science Forum, 968, pp. 450-459.

[17] Kukla, S.; Skalmierski, B. 1993: The effect of axial loads on transverse vibrations of an Euler-Bernoulli beam, Journal of Theoretical and Applied Mechanics, 31 (2), pp. 413-430.

[18] Krutii, Yu.; Vandynskyi, V. 2019: Exact solution of buckling problem of the column loaded by self-weight, IOP Conference Series: Materials Science and Engineering, 708, p. 012062. https://doi.org/10.1088/1757899X/708/1/012062

[19] Wang, C. M.; Wang, C. Y.; Reddy, J. N. 2005: Exact solutions for buckling of structural members, CRC series in computational mechanics and applied analysis, Boca Raton, Florida, USA https://doi.org/10.1201/9780203483534

Krutii, Y, Vandynskyi, V, Konstantinov, P 
[20] Volmir, N. S. 1963: Ustoychivost uprugih system [in Russian], Fizmatgiz

[21] Birger, I. A.; Panovko, Ya. H. 1968: Prochnost', ustoychivost', kolebaniya: spravochnik v 3 tomah [in Russian], Mashinostroyeniye

Please cite this article as: Krutii, Y.; Vandynskyi, V.; Konstantinov, P.: Analytical Calculations of the Vibrations of Vertical Structures Considering Their Dead Weight, Electronic Journal of the Faculty of Civil Engineering Osijek-eGFOS, 2021, 22, pp. 29-40, https://doi.org/10.13167/2021.22.3

Krutii, Y, Vandynskyi, V, Konstantinov, P 